\title{
UPDATE ON THE RANGE AND DISTRIBUTION OF BLUE-SPOTTED SALAMANDERS IN MANITOBA
}

Shauna Hewson ${ }^{1}$, William G. Watkins ${ }^{2}$

12115-991 Markham Road, Winnipeg Manitoba, R3T 5K1; E-mail: <shauna.hewson@ live.ca>

2Manitoba Conservation, Winnipeg, MB R3J 3W3; E-mail: <william.watkins@gov. mb.ca>

\section{Introduction}

The blue-spotted salamander (Ambystoma laterale) is one of Manitoba's most secretive amphibians. This trait has prevented most researchers from collecting comprehensive data about its population numbers, range, and distribution in Manitoba's boreal forests. Since 1982, the most informative range data available have come from Preston's book on the amphibians and reptiles of Manitoba. ${ }^{1}$ Preston proposed a hypothetical range for this species that includes Manitoba's southeast corner, extends west to the Brokenhead River and north partway into the Interlake region. Several specimens were collected at Riverton during that time, which served to delineate the northern range limit of the species. ${ }^{1}$

The blue-spotted salamander is black to light grey in colour, with small blue spots on its ventral surface, lateral surface, and tail. ${ }^{1,2}$ This spot pattern is highly variable, and spot colour can range from bright blue to very pale blue or almost white..$^{1,2}$ The blue-spotted salamander has several qualities that make it difficult to survey. Its small size (average $130 \mathrm{~mm}$ in length) allows it to utilize any number of small animal burrows, crevices inside rotten logs, or piles of rotting leaf debris on the forest floor ${ }^{1,2}$ Adults and juveniles avoid sunlight, and thus are almost never seen out in the open during daylight hours. ${ }^{1,2}$ They feed on groups of arthropods and other small invertebrates normally found in these microhabitats..$^{1,2}$ Salamander surveys are very labour intensive because even a small survey area in a boreal forest could contain hundreds of possible niches for adults to hide in. It seems that their terrestrial movement is infrequent, so that even above-ground traps or cover boards have limited success for surveys. ${ }^{3}$

During the summer of 2008, Manitoba Conservation updated provincial status ranks for all amphibians and reptiles in Manitoba. Status ranking involves evaluating all information available for each species to assign a status rank that accurately reflects the scope of current knowledge on species range and abundance. ${ }^{4}$ Assigning a rank to the bluespotted salamander was difficult due to the minimal number of valid sightings reported since 1982. Local naturalists suggested that these animals should be classified as abundant, although a decision to do so would have to be based mostly on anecdotal reports and limited sightings. As a compromise, blue-spotted salamanders were tentatively ranked as 'S3/S4' pending 
completion of the surveys described in this paper. A rank of S3/S4 suggests that the species is considered widespread, abundant, and apparently secure, but there is some uncertainty or lack of data to support this assumption. ${ }^{4}$

Presence/absence surveys are generally used to record a measure of proportional occupancy in a given area. ${ }^{5}$ For the purpose of this study, the method was utilized to examine Preston's proposed range for the species in Manitoba. ${ }^{1}$ Two potential weaknesses of this survey style have been identified. ${ }^{5}$ First, it is not a reliable indicator of abundance because presence/absence surveys can over- or under-represent a population. This disguises population declines and overlooks population growth. Second, the chance of species detection can fluctuate due to temporal and spatial dynamics of a population, making survey results ambiguous $^{5}$ (see also reference 6). Our focus was on finding new sites, rather than estimating abundance, in order to avoid some of these shortcomings.

\section{Methods}

Surveys for blue-spotted salamanders began in May and were completed in July 2009. Survey sites were chosen based on current Conservation Data Centre (CDC) records or Manitoba Museum records. All sites of interest were located or situated in the southeast corner of the province, east of Highway 59 and north to the limit of Provincial Road 304 near Bissett. The first surveys examined known or previously reported but unconfirmed locations to allow surveyors to develop a habitat and species search image. Later surveys examined new locations. All new site occurrences discovered were mapped in the CDC's GIS database.

Two survey methods were used to look for blue-spotted salamanders. In spring and early summer, aquatic surveys were conducted to look for eggs and larvae. Later in the summer, terrestrial surveys were used to locate adult specimens. In total, 39 sites were surveyed.

From 1 May to 30 June, aquatic searches were performed at Star Lake in Whiteshell Provincial Park, Grand Beach Provincial Park, Sandilands Provincial Forest, and East Braintree (just west of Whiteshell Provincial Park along Highway 1). An underwater viewer facilitated examination of benthic areas in ponds, vernal pools (temporary woodland pools created by melting snow and spring rains), and ditches. The $28 \times 28 \mathrm{~cm}$ viewer allowed surveyors to walk slowly while examining the benthos along $28 \mathrm{~cm}$ wide transects across the bottom of the water body. When multiple surveyors were present, one observer used the viewer while others searched the benthos without visual aid. Dip nets were used to catch larvae and confirm their identity. We discovered that the most useful technique involved placing the open dip net $30 \mathrm{~cm}$ ahead of the organism and then shuffling toward it so that it swam into the net and could be examined.

Terrestrial surveys were conducted following a previously established protocol. ${ }^{7}$ Survey locations included sites at Grand Beach, Agassiz Provincial Forest, Patricia Beach, Brokenhead, Gull Lake, Whiteshell Provincial Park, and Nopiming Provincial Park. Habitat was deemed suitable if it contained mixed forest, deciduous brush areas, fallen logs, or any natural or manmade object that might provide a covered microhabitat for salamanders. An area with an approximate radius of $100 \mathrm{~m}$ was randomly delineated within suitable habitat, and timed searches of 20 minutes duration were performed by two surveyors within this area. Surveyors worked from the interior to the periphery of the study area. On each transect, we turned over logs, boards, and other man-made objects 
such as buckets or tin cans. If the edge of the site was reached before the allotted 20 minutes had expired, the surveyor would continue searching, moving back to the interior until time ran out. Variability in the amount of downed material would dictate the total area surveyed, but the number of hiding sites searched in 20 minutes was relatively consistent between sites.

\section{Results and Discussion}

Aquatic surveys were unsuccessful in locating salamander eggs or larvae. No eggs were found during the course of the study, and larvae were seen at only one site near Star Lake. The underwater viewer greatly improved our ability to search the benthos, but, despite the most careful search techniques, salamander eggs are easily missed due to their transparent appearance (which camouflages well in benthic sludge) and their typically small clusters of three or four eggs. Larvae become easier to see several weeks after hatching as their size and range of activity increases on the pond bottom. The first larva was spotted in a borrow pit pond near Star Lake in early June and measured $\sim 5$ $\mathrm{mm}$ long. The second larva was found in the same pond in late June and measured ca. $15 \mathrm{~mm}$ long (Fig. 1).

Terrestrial surveys were far more successful than the aquatic surveys in finding new locations for blue-spotted

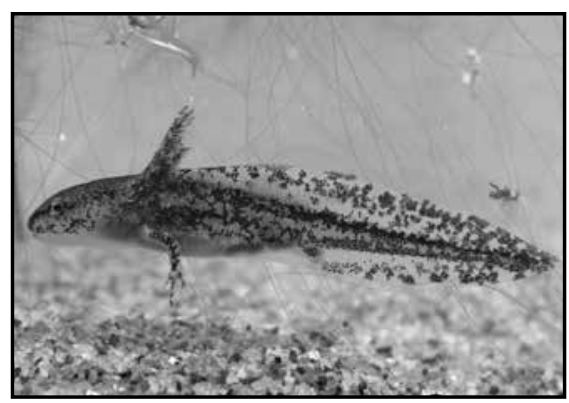

Figure 1. Larval blue-spotted salamander near Star Lake, Manitoba, in late June 2009.

Doug Collicut salamanders. We found adult blue-spotted salamanders at four new locations: Werner Lake Road, Gull Lake, and two locations around Flanders Lake. Additional sightings were confirmed from sources in Beausejour, Grand Beach, Moose Lake, Pelican Harbour, Pinawa, Rennie, and Washow Bay.

In total, 19 sites with blue-spotted salamander populations were mapped, including the pond where larvae were discovered, three sites catalogued at the Manitoba Museum, the new locations cited above, and 11 sites contributed by the general public or Manitoba Conservation employees that were confirmed by photographs or site visits (Fig. 2).

The adult specimens found on Werner Lake Road and around Flanders Lake were sitting in substrate containing pine needles. This seemed to contradict the popular notion that salamanders avoid areas with coniferous trees. The largest group of adults $(n=7)$ counted at one location were nestled into a pile of damp, coarse gravel covered with a tarpaulin. The adults found near Gull Lake were lying in a mixed substrate containing mostly sandy soil and gravel, a substrate that agrees with the habitat previously suggested for this species. ${ }^{1}$

We discovered that sites with human activity were hotspots for adult salamanders since cottager activity provided favourable habitat. Loose plywood, shingles, and cardboard piles were frequently seen with one to seven salamanders congregated underneath. It was noted that these garbage piles were often covered with a tarpaulin, making them warm and very moist, supporting large amounts of invertebrate life. This affinity for cast-off debris may prove useful for establishing new locations for blue-spotted salamanders in the future. Much of their range contains cottage developments on lake shores 


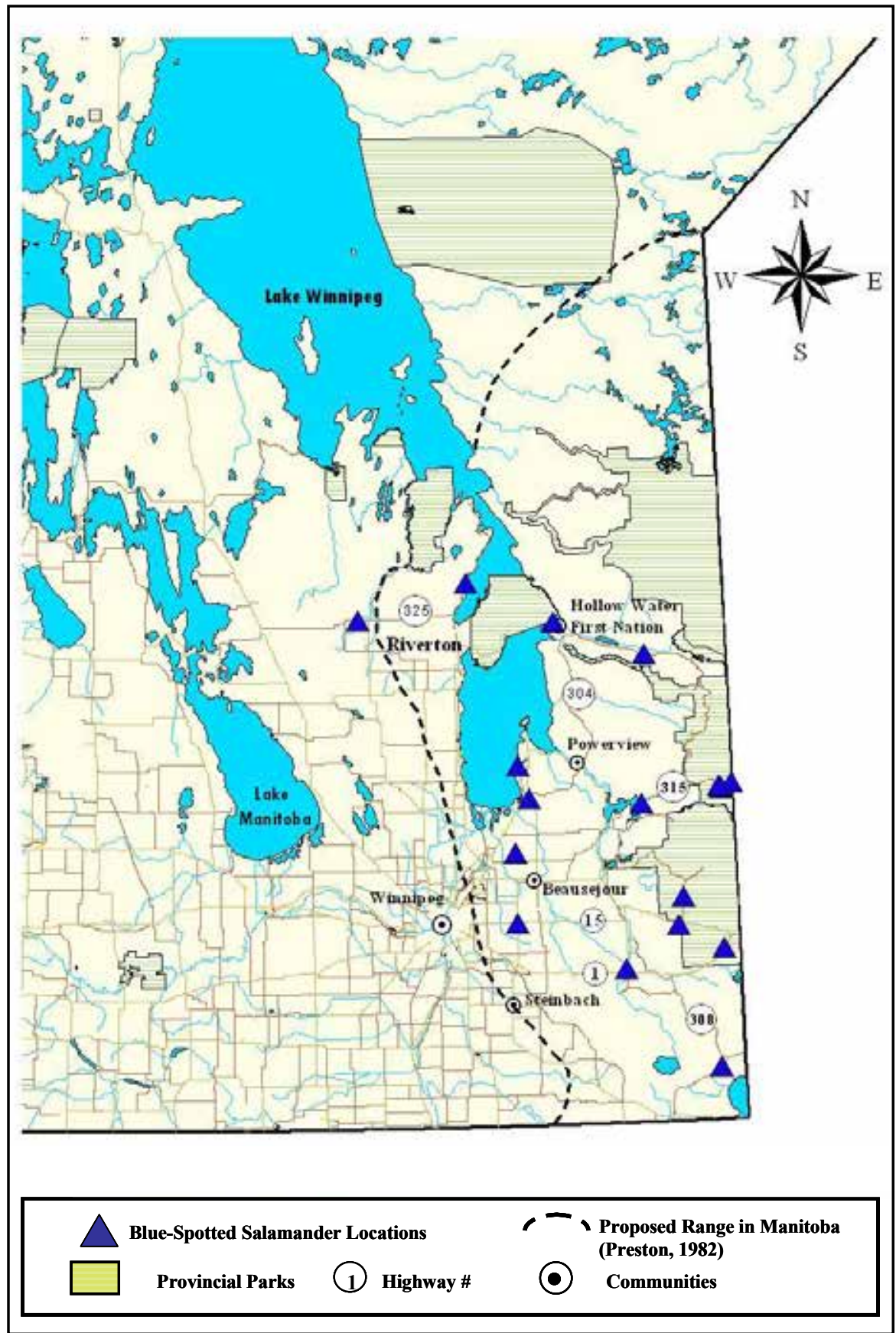

Figure 2. Blue-spotted salamander locations in southeastern Manitoba. 
with these artificial salamander habitats. We believe that future presence/absence surveys in Nopiming Provincial Park would contribute data points to fill out the northern portion of Preston's range map, and that the observations described above provide an easy search image to use when surveying around lake areas. ${ }^{1}$

\section{Promoting Awareness of Manitoba's Herpetofauna}

During the summer of 2009, Manitoba Parks and Natural Areas Branch invited Winnipeg biologist Doug Collicutt and one of the authors (S. H.) to give presentations on the amphibians and reptiles of Manitoba to park visitors in Whiteshell Provincial Park. On 3 July, the first of two presentations was held at the Falcon Lake Campground Amphitheatre, attracting 157 people. A Powerpoint presentation was used to discuss the ecology and conservation status of Manitoba species and the rationale for monitoring and conserving herpetofauna. The audience was also shown how to identify frogs by their appearance and calls. The final part of the presentation was an informal question and answer period that involved a live demonstration of captive specimens. Audience members were able to view and discuss 14 species, and to review the identification points from the formal presentation.

On 14 August, a more hands-on approach was used at Brereton Lake Campground. Live specimens were circulated around the audience and spectators were invited to participate in a discussion about the animals. Topics discussed included physical traits, frog call identification, basic ecology of the organisms presented, and basic safety and handling techniques for observing reptiles and amphibians.

These presentations served two purposes: first, they were designed to make Manitobans aware of all species of herpetofauna within the province. This was especially important for species like the blue-spotted salamander, because its reclusive lifestyle makes it unknown to most people. Second, we were able to encourage Manitobans to participate in developing an on-line reptile/amphibian atlas for the province on Doug Collicutt's NatureNorth website. NatureNorth. com (http://www.naturenorth.com/) is a Manitoba-based internet magazine focusing on Manitoba's natural history. The atlas project will involve establishing a citizen-science network to report sightings of all reptile and amphibian species leading to a better understanding of the range and status of these species in Manitoba. Eventually, individuals will be able to post observations or data related to amphibians and reptiles directly to the website.

Presenting the public with an opportunity to learn about Manitoba's amphibian and reptile species is important. Education empowers people to share their newly acquired knowledge with others and increases public awareness for species of concern. In turn, this awareness serves to foster a natural curiosity in people as they gain a new understanding of natural ecosystems and become interested in spotting these creatures themselves. Also, awareness and interest in species facilitates the development of a network of knowledgeable observers able to accurately report sightings. In the weeks following our seminars, we learned of the studies being conducted on bluespotted salamanders in Pinawa by Peter Taylor (this issue) and were able to share observations with him. Members of the public also sent in several sightings for blue-spotted salamander in regions that we were not able to cover in our 2009 surveys. One of these sightings came from Washow Bay and is now the most northern range sighting known for this species (see Fig. 2). 


\section{Conclusion}

Blue-spotted salamander surveys in the summer of 2009 yielded five new location records for the species (one pond with larvae and four terrestrial sites with adults) out of 39 locations searched. In contrast, soliciting observations from the public and Manitoba Conservation staff resulted in 11 new records. Several of the newly located sites were adjacent to cottage subdivisions where salamanders were found to be utilizing human refuse piles for shelter and food. Blue-spotted salamanders may be abundant around lakes within Whiteshell and Nopiming Provincial Park and the Interlake Region, and more effort to provide information on the species to cottagers may be rewarded with additional observations. Given the secretive nature of the species, developing a network of knowledgeable volunteer observers that can collectively examine thousands of sites may be the best approach to further define the range of blue-spotted salamanders in Manitoba.

Although Preston's 1982 range map for blue-spotted salamanders was based on a relatively small number of observations, only one of our new site locations lies outside of his proposed range for the species. ${ }^{1}$ However, we were unable to survey sites north of Nopiming Provincial Park to test the validity of the range boundary in the north east. We hope that within the next few years, more data will be collected to further define the range of the species in Manitoba.

Blue-spotted salamanders appear to be secure within their range in Manitoba but, with the absence of any clear understanding of threats to the species, a lack of population data, and the uncertainty regarding the extent of the species range east of Lake Winnipeg, conservation status must remain $\mathrm{S} 3 / \mathrm{S} 4$ at this time.

\section{Acknowledgements}

We thank Diane Kunec, Garret Elias, Mahesh Kalia, Chris Friesen, and Christian Artuso for their enthusiastic participation in our surveys, and Jaimee Dupont for help with mapping location data. We also thank Manitoba Parks and Natural Areas Branch for the opportunity to present information on Manitoba's amphibians and reptiles to park visitors. We are grateful to Peter Taylor for helpful discussions regarding our observations. Finally, we thank Doug Collicut for his enthusiastic support of the project, his participation on surveys, and his guidance on field techniques, and for sharing opportunities to reach out to the public. We also extend our thanks to Doug for allowing us to include his blue-spotted salamander larva photo in this article.

1. Preston WB (1982) The Amphibians and Reptiles of Manitoba. Manitoba Museum of Man and Nature, Winnipeg, MB.

2. Cook FR (1984) Introduction to Canadian Amphibians and Reptiles. National Museum of Natural Sciences (Canada), Ottawa, ON.

3. Regosin JV, Windmiller BS, Homan RN, Reed JM (2005) Terrestrial habitat use by pool-breeding amphibians. Journal of Wildlife Management 69(4):1481-1493.

4. Manitoba Conservation Data Centre (2004) Species Ranking. Manitoba Conservation, Winnipeg.

5. Milner-Gulland EJ, Rowcliffe JM (2007) Conservation and Sustainable use: a Handbook of Techniques. Oxford University Press, Oxford.

6. De Solla SR, Shirose LJ, Fernie KJ, Barrett GC, Brousseau CS, Bishop CA (2005) Effect of sampling effort and species detectability on volunteer based anuran monitoring programs. Biological Conservation 121(4):585-594.

7. Zorn P, Blazeski V, Craig B (2004) Joint EMAN/Parks Canada National Monitoring Protocol for Plethodontid Salamanders. Version 1, July. Environment Canada. 